of concurrent valproate therapy when possible, may lessen the risk of serious rash.

\title{
VIGABATRIN FOR INFANTILE SPASMS
}

The efficacy of vigabatrin (VGB) as the first, and adrenocorticotropin hormone (ACTH) or valproate (VPA) as the second, treatment of choice for newly diagnosed infantile spasms was evaluated in 42 infants treated at the University of Helsinki, Finland. Response was measured by total control of spasms for a minimal duration of 1 month and confirmation by video-EEG. Spasms were cryptogenic in 10 and symptomatic in 32 . Vigabatrin $(50-100 \mathrm{mg} / \mathrm{kg} /$ day) controlled spasms in 11 (26\%); 5 were cryptogenic and 6 symptomatic. ACTH offered in combination with VGB in 22 and VPA in 4, not controlled by VGB alone, were effective in $11(50 \%)$ and 1 (25\%), respectively. Overall, 26 (62\%) infants responded to treatment; $100 \%$ response with cryptogenic cases and 50\% with symptomatic etiology. Side effects were more severe with ACTH than VGB or VPA. Relapse after a spasm-free period of $>4$ months occurred in only 1 infant treated with VGB, but in none who received ACTH combined with VGB. ACTH should be considered after an initial trial of VGB in increasing doses from 50 to $150 \mathrm{mg} / \mathrm{kg}$ for $10-14$ days. (Granstrom M-L, Gaily E, Liukkonen E. Treatment of infantile spasms: results of a population-based study with vigabatrin as the first drug for spasms. Epilepsia July 1999;40:950-957). (Reprints: Dr M-L Granstrom, Epilepsy Unit, Hospital for Children and Adolescents, University of Helsinki, Lastenlinnantie 2, 00250 Helsinki, Finland).

COMMENT. Vigabatrin is suggested as the first treatment for all infants with infantile spasms. In non-responders, ACTH should be considered. Response should be confirmed by video-EEG of 3-4 hours during waking and sleep, and visual responses should be carefully monitored when practical. Etiology of spasms is the most important determinant of treatment outcome; cryptogenic cases benefit more frequently than those with acquired causes. Most infants with symptomatic etiology are mentally retarded at follow-up. See Ped Neur Briefs (June 1999;13:47) for report of a previous study of ACTH cf vigabatrin in infantile spasms. In one study, VGB was recommended as first-line therapy for infantile spasms. In another, also from Finland, asymptomatic visual field constriction is reported in 2 children treated with VGB.

Vigabatrin-induced aminoaciduria. Fourteen children treated for epilepsy in Sheba Medical Center, Tel-Aviv University, Israel, had increased urinary excretion of amino acids, particularly B-alanine, g-aminobutyric acid, and B-aminoisobutyric acid, while receiving VGB. (Lahat E et al. Pediatr Neurol July 1999;21:460-463). A metabolic screen, including amino acid and organic acid analyses, is recommended prior to starting VGB therapy for seizures.

Aminoaciduria and epilepsy. Hyperaminoaciduria has been reported previously in children with absence and other idiopathic epilepsies (Millichap JG, Ulrich JA. Mayo Clin Proc 1962;37:307; Millichap JG, Jones JD. Epilepsia 1964;5:2349). The abnormal excretion was not associated with renal disease and could not be explained as a side effect of antiepileptic medication. In fact, the hyperaminaciduria was decreased during therapy with AEDs (trimethadione, phenobarbital, mephobarbital) or the ketogenic diet, suggesting a correlation between the aminoaciduria and epilepsy.

Ketosis and epilepsy. P31 magnetic resonance spectroscopic imaging studies were performed in 7 patients with intractable epilepsy, before and after the ketogenic diet. Significant increases in high-energy phosphates and metabolism occurred with the diet. (Pan JW et al. Epilepsia June 1999;40:703-707). 
Epidemiology of infantile spasms. Cumulative incidence of IS among Atlanta children is 2.9/10,000 live births. Among 10-year-olds with a history of IS, $83 \%$ are mentally retarded (MR), with no difference between cryptogenic and symptomatic cases. Of 10-year-olds with profound MR, $12 \%$ have a history of IS. Fifty percent of IS patients develop Lennox-Gastaut syndrome before age 11 years. (Trevathan E, Murphy CC, Yeargin-Allsopp M. The descriptive epidemiology of infantile spasms among Atlanta children. Epilepsia June 1999;40:748-751).

\section{SEIZURE DISORDERS}

\section{OCCIPITAL EPILEPTIFORM DISCHARGES AND EPILEPSY}

The frequency of different causes of occipital epileptiform discharges (OEDs) and EEG features predictive of epilepsy type and outcome were analyzed in 90 children with OEDs examined at the Floating Hospital for Children, Tufts University School of Medicine, Boston, MA. More than one half (56\%) had seizures symptomatic of underlying illness, including cerebral palsy (18), cerebral dysgenesis (11), and genetic disorders (8). One third had idiopathic seizures, including 6 with benign childhood epilepsy with occipital paroxysms, 1 with febrile seizures, and 8 had no seizures. Only 2 had visual symptoms with seizures. Background slowing in the EEG was associated with symptomatic seizures in $87 \%$; normal background EEG activity was present in $87 \%$ of those with idiopathic seizures $(\mathrm{p}<0.001)$. At follow-up in 72 cases, $62 \%(28$ of 45$)$ of those with normal EEG background had seizure remission compared to $37 \%$ (10 of 27) of those with background slowing $(\mathrm{p}=0.04)$. Generalized spike-wave discharges correlated with idiopathic epilepsy and a better prognosis. (Libenson $\mathrm{MH}$, Caravale B, Prasad AN. Clinical correlations of occipital epileptiform discharges in children. Neurology July 1999;53:265-269). (Reprints: Dr Mark H Libenson, Division of Pediatric Neurology, New England Medical CVenter Box 330, 750 Washington Street, Boston, MA 02111).

COMMENT. Most epilepsies with occipital epileptiform discharges on the EEG are symptomatic and associated with developmental delay or severe behavior problems or both. A normal background rhythm or generalized spike-wave in the EEG correlates with idiopathic seizures and a better prognosis.

Early-onset benign childhood epilepsy with occipital paroxysms was identified by the necessary 5 diagnostic criteria in 19 of 649 children with localization-related epilepsies followed at the Tokyo Women's Medical College, Japan. An additional 22 exhibited all criteria except occipital EEG foci, and 21 lacked only ictal vomiting. Of a total of 57 patients, $74 \%$ were in remission by age 12 years. The remission rate was similar in those with or without ictal vomiting. The clinical spectrum of the syndrome is broad, and the diagnostic criteria require further clarification. (Oguni H et al. Epilepsia July 1999;40:1020-1030).

\section{NEUROBEHAVIORAL DISORDERS}

\section{NEUROBEHAVIORAL RISK FACTORS IN SCHIZOPHRENIA}

Neurobehavioral deficits in the offspring of schizophrenic parents compared to offspring of parents with no or nonschizophrenic mental disorder were analyzed in 65 Israeli adolescents enrolled in the Jerusalem Infant Development Study. Poor neurobehavioral functioning, assessed by a battery of neurologic and neuropsychological tests and psychiatric interviews, was found in $42 \%(10 / 24)$ of offspring of schizophrenic parents ( $73 \%$ of the male offspring), 